This item was submitted to Loughborough's Research Repository by the author.

Items in Figshare are protected by copyright, with all rights reserved, unless otherwise indicated.

\title{
British airways' move to Terminal 5 at London Heathrow airport: a statistical analysis of transfer baggage performance
}

PLEASE CITE THE PUBLISHED VERSION

http://www.sciencedirect.com/science/article/pii/S0969699710000876

PUBLISHER

(C) Elsevier

VERSION

AM (Accepted Manuscript)

LICENCE

CC BY-NC-ND 4.0

\section{REPOSITORY RECORD}

Heinz, S.F., and D.E. Pitfield. 2019. "British Airways' Move to Terminal 5 at London Heathrow Airport: A Statistical Analysis of Transfer Baggage Performance". figshare. https://hdl.handle.net/2134/8972. 
This item was submitted to Loughborough's Institutional Repository (https://dspace.lboro.ac.uk/) by the author and is made available under the following Creative Commons Licence conditions.

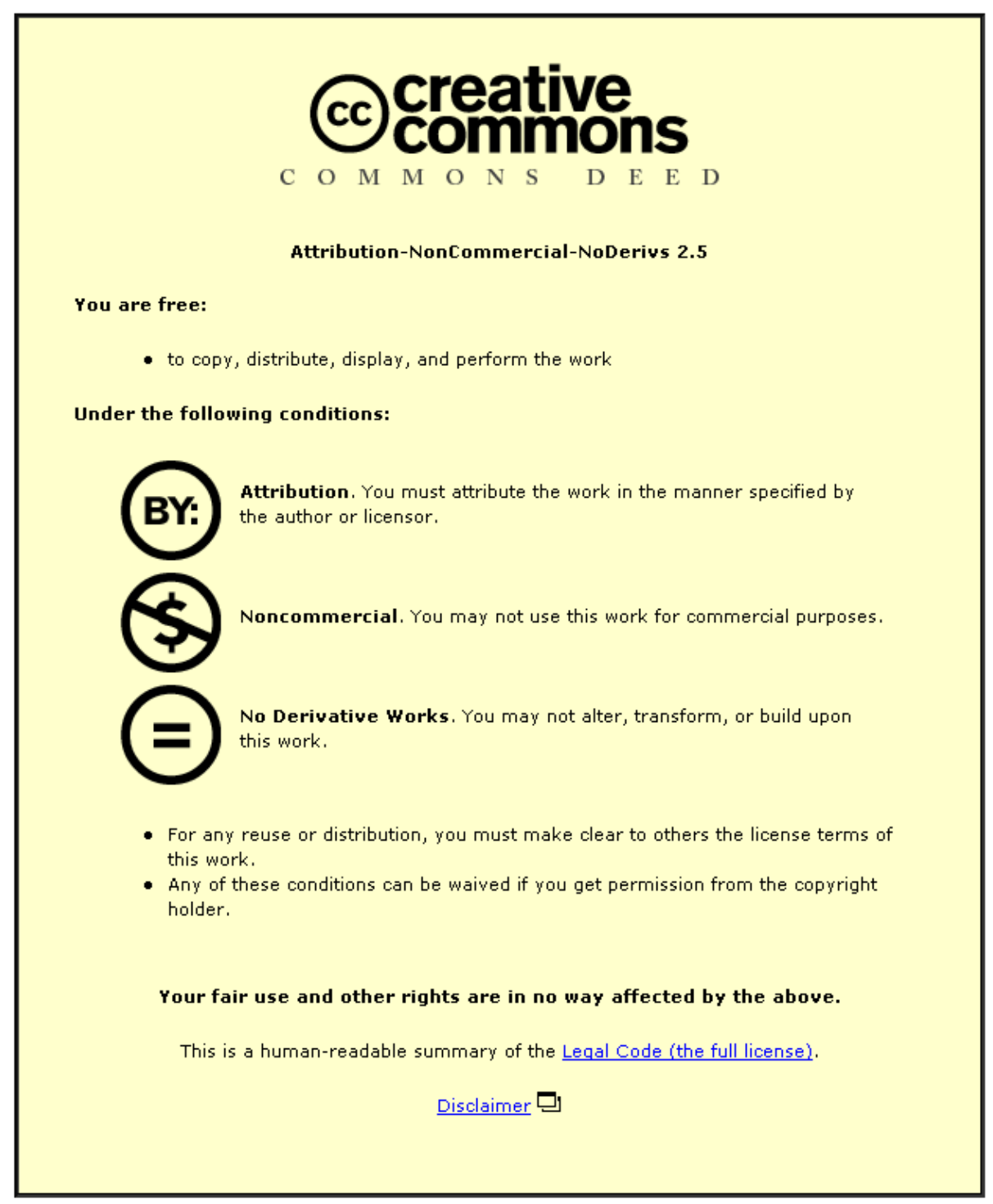

For the full text of this licence, please go to: http://creativecommons.org/licenses/by-nc-nd/2.5/ 
British Airways' move to Terminal 5 at London Heathrow Airport: A statistical analysis of transfer baggage performance.

\author{
S.F.Heinz and D.E.Pitfield \\ Transport Studies Group \\ Department of Civil and Building Engineering \\ Loughborough University \\ Loughborough \\ Leicestershire LE11 3TU \\ UK \\ E-mail: D.E.Pitfield@lboro.ac.uk
}

\begin{abstract}
This paper investigates transfer baggage performance as British Airways’ occupancy of Terminal 5 at London Heathrow Airport took place.

Operational data on transfer baggage performance is collated from BA performance scorecards and the Gini coefficient is proposed as a measure of consolidation of flight operations within a single terminal. This coefficient is then used in investigations of correlation of consolidated flights in Terminal 5 with transfer baggage performance variation. The relationship between consolidation of operations in the terminal and improving transfer baggage performance is found to be significant, implying the existence of a causal relationship. In addition, there is also evidence of significant changes in transfer baggage performance on switch phases of flights as they were moved to Terminal 5 in steps. There seems to be evidence that suggests the exclusive use of a terminal gives improved performance.
\end{abstract}




\section{Introduction}

As well as providing cost benefits, largely in terms of manpower savings, the consolidation of operations under one roof in Terminal 5 (hereafter, T5) represented a wide array of benefit for British Airways (hereafter, BA) according to Doherty (2008). The airline presented T5 as providing an improved overall customer experience, increased transfer efficiencies (of both passengers and baggage) and opportunities for increasing awareness of the BA brand. Current research does investigate such benefits, however, only in the context of shared terminal use, whereby they are discussed as disadvantages associated with shared facilities. It is not surprising therefore, that empirical investigation of such benefits is largely lacking when focusing on the benefits of single terminal use and this is something which this paper aims to address.

\section{Airport Terminals: Contextual background}

The operational benefits afforded to airlines through the use of single-user terminals and airline branding and image have always been central to the issue of such exclusive use. The Airports Cooperative Research Program, hereafter ACRP (2008) highlights a number of operational implications of single-user terminals, some of which can be considered advantageous, at least to the occupying airline, the airport authority or indeed the airline's customers.

It suggests that geographical factors as well as different government and ownership scenarios also lie behind varying global approaches to terminal use. 
"In Europe for example the close proximity of multiple countries makes the majority of flights international. Because these airports support more international flights, they have been more disposed to implementing common use. Historically, airports in the United States were developed in conjunction with a flagship carrier. These relationships resulted in long leases and created the hub airport. European airports were developed mostly by governments and therefore do not have as many long-term leases with flagship carriers.” (ACRP 2008, p.12)

The degree of exclusive terminal use witnessed in the US from the 1950s up until the 1980s was unparalleled in Europe.

It is clear that the composition of airlines serving a given airport is an influential factor in the drive along the common use continuum, either towards exclusive use or common use as outlined by both Wells and Young (2004) and the ACRP (2008). Indeed while there exist traffic profiles and schedule structures that do not fully support a philosophy of exclusive-use, there exist those that do. It is logical to assume that if traffic profiles with significant peaking support shared-use to utilise facilities effectively, those with a flatter trend across the day will be more conducive to exclusive use. Furthermore, airlines with fuller schedules are more likely to benefit from single-user terminals than those with sparser schedules.

With regards to the BAA's decision to allow BA sole occupancy of T5, Doherty (2008, p.52) states “BA represents around 40\% of traffic at Heathrow and its mix of domestic, short- and long-haul traffic generally offers a flat daily profile of traffic that allows the infrastructure to be used 
effectively throughout the day.” Doherty (2008), however, does not provide clear evidence besides that of BA's schedule or traffic structure as supporting exclusive terminal use. Dennis (1994) suggests that the efficiency of airports at processing connecting passengers and baggage can be measured by the respective airport terminal's minimum connection time (MCT) and the MCT for connections within T5 is calculated as 60 minutes, significantly lower than the average MCT of 87 minutes for connections between terminals at Heathrow (OAG World Airways Guide, 2009). Another, albeit partial measure of efficiency, is of transfer baggage and this is the primary empirical focus of this paper.

\section{Data and Methods}

\subsection{Baggage Data}

Although BA is not currently [May 2010] exclusively based in T5, T5 is exclusively a BA terminal. The transfer of flights into T5 occurred gradually over a period of time from the $27^{\text {th }}$ March 2008 to the $22^{\text {nd }}$ October 2008 (Heathrow Customer Services (HCS), 2007). This gradual consolidation of operations allows for analyses linking transfer baggage performance trends over time (from the $27^{\text {th }}$ March 2008 to the $31^{\text {st }}$ May 2009) with increasing consolidation of operations over the same period of time, opposed to merely comparing pre-T5 performance with post-T5 performance, should flights have moved into the terminal over a single night.

Transfer baggage performance data is collected at BA using a data feed provided by the BAA’s baggage tracking system, known as Merlin. The Merlin data output was fed into the BA central data warehouse (known as 
the OAW - Operational Activities Warehouse) from where it was accessed using Business Objects Software as a user-friendly interface. Figure 1

illustrates this data collection process.

The resulting datasheet, forming part of the T5 Daily Performance

Scorecard, included 430 entries (one for each day from $27^{\text {th }}$ March 2008 to the $31^{\text {st }}$ May 2009) measuring daily transfer baggage performance, the main measure of which is the absolute number of short-landed ${ }^{1}$ bags per thousand passengers flown (Saxton and Korac-Kakabadse, 2003). For the purpose of this research the focus was on BA-BA connections only, excluding transfers between other carriers and BA, in line with the aim of determining the effect that consolidation of operations of a single airline's flights in one terminal may have on that airline's transfer baggage performance ${ }^{2}$.

Figure 1: Transfer Baggage Performance data collection process Source: Adapted from HCS Microsite LHRPerf , 2010

\section{Baggage Tracking Svstem}

Data Software Output

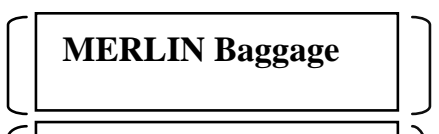

BAA

\begin{tabular}{|l|}
\hline Operational \\
Activities \\
Warehouse
\end{tabular}

Business Objects

Microsoft Excel

T5 Daily

Performance

Scorecard

\footnotetext{
${ }^{1}$ Short-landed bag: A bag that does not arrive at the desired destination with the corresponding passenger (Saxton and Korac-Kakabadse, 2003).

${ }^{2}$ On average BA-BA connections make up about $80.69 \%$ of total transfer bags per day.
} 


\subsection{Flight Data}

In order to effectively assess the relationship between transfer baggage performance and consolidation of operations in T5, the exact flight volumes in each terminal concerned were collected over time. This volume data would essentially highlight daily and weekly variations in the schedule but also highlight key dates on which flights were 'switched' between terminals. This data was collected in much the same way as transfer baggage performance data, in that it originated in the OAW data warehouse and was collected via Business Objects software before being presented on the T5 Daily Performance Scorecard. The flight data and baggage data are compatible as they are from the same source.

\subsection{Gini Coefficient as a Consolidation Measure}

To assess the influence of increasing consolidation of BA's operations in a single terminal on transfer baggage performance requires the investigation of a relationship between transfer baggage performance and consolidation of operations. In order to effectively carry this out, both elements of transfer baggage performance and terminal consolidation required a metric. While for transfer baggage performance this is in the form of short-landed bags per thousand passengers, the metric for terminal consolidation is slightly more complex.

To further understand how the degree of consolidation of operations in a single terminal could be measured, parallels were drawn between investigating to what extent an airline has consolidated its operations in a single terminal and to what extent an airline has developed a route network based on a hub. Both cases deal with an investigation of equality of 
distribution, the former looking at distribution of flight volumes between terminals and the latter, the distribution of traffic between airports. It is this notion of equality of distribution that leads the investigation to Ginimethodology, first introduced to air transport analysis by Reynolds-Feighan (2001) for the measurement of spatial concentration in airline networks.

For the purpose of this paper, the formula proposed by Rodrigue et al (2009, p 186) was used to calculate the Gini coefficient.

$$
G=1-\sum_{i=1}^{N}\left(X_{i}^{c p}-X_{i-1}^{c p}\right)\left(Y_{i}^{c p}+Y_{i-1}^{c p}\right)
$$

In the above equation $X$ refers to the traffic proportion if the traffic was distributed evenly throughout all the terminals. $Y$ refers to the actual proportion of traffic at each terminal. $X^{c p}$ and $Y^{c p}$ are cumulative proportions of $X s$ and $Y s$ and $N$ is the number of elements or observations with $i$ denoting the terminals.

\section{Results}

\subsection{Trends in Baggage Data}

It is important to gain an understanding of the trends of both transfer baggage performance and the Gini coefficient over the time period under investigation before they are investigated using ANOVA and correlation. Based on data collected from the T5 Daily Performance Scorecard, Figure $2^{3}$ represents transfer baggage performance based on the measure of shortlanded transfer bags per thousand passengers for BA-BA connections only.

\footnotetext{
3 The y axis values are missing to preserve the confidentiality of the raw data.
} 
Figure 2 highlights a number of interesting characteristics regarding the nature of the data. As would be expected, the first few weeks following T5's opening show a poor performance, with high values of short-landed bags per thousand passengers. This corresponds with the time during which the terminal experienced significant operational issues including, but not exclusively, baggage system failures and poor staff training on new systems. The data also shows, however, that within a month after the opening of the terminal, transfer baggage performance had reached a relatively stable level. Of course, as highlighted by Figure 2, baggage performance is significantly volatile, being sensitive to influences such as poor weather and flight cancellations. This goes some way to explaining the occasional extreme peaks in the data, emphasising that some sort of outlier exclusion technique should be implemented before the data can be applied to studies of ANOVA and correlation.

Figure 2: Transfer Baggage Performance trend

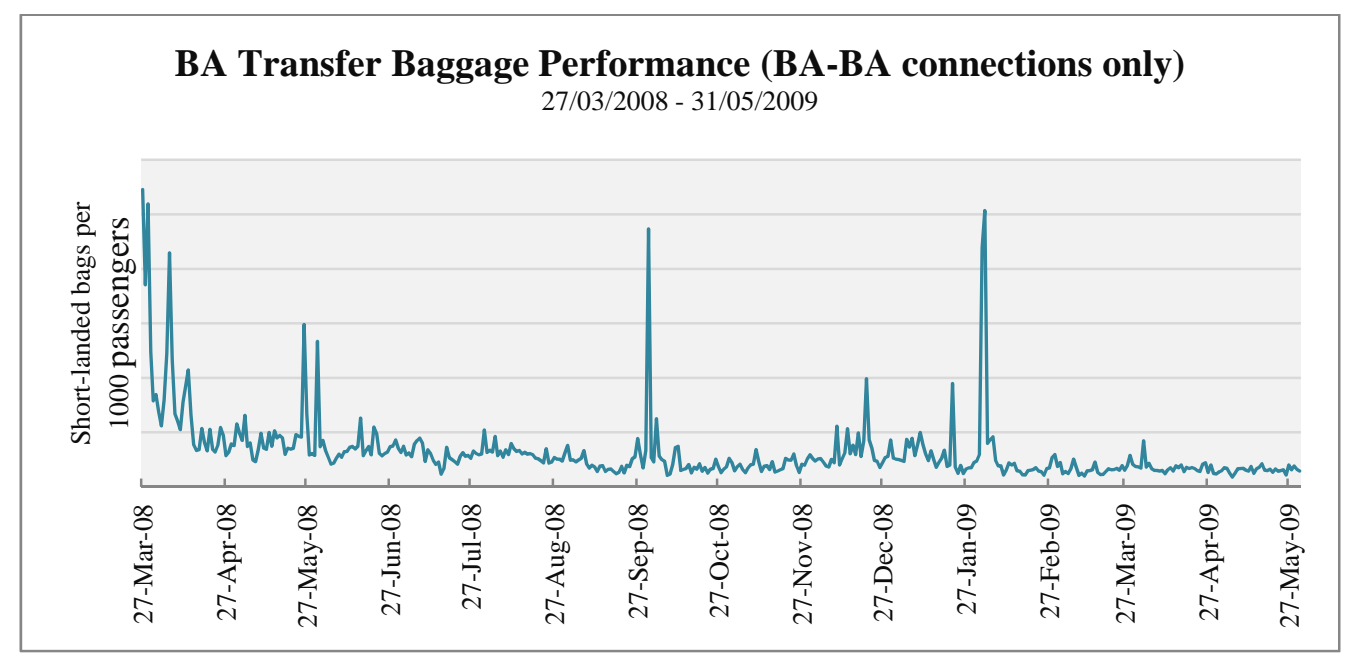




\subsection{Trends in Gini Coefficient}

Key to the consolidation of BA operations in T5, were the 'flight switches' which occurred between $27^{\text {th }}$ March 2008 and $31^{\text {st }}$ May 2009. Switches refer to the movement of flights between terminals which occurred on predetermined dates, with the aim of ultimately moving all flights into T5 (Heathrow Customer Services (HCS), 2007). Table 1 represents a summary of these switches.

\section{Table 1: BA flight switches}

\begin{tabular}{|l|l|l|l|l|}
\hline Date & Switch & From Terminal & To Terminal & Flights \\
\hline $27 / 03 / 08$ & 1 & 1 and 4 & 5 & $\begin{array}{l}\text { All routes from T1 excluding } \\
\text { Barcelona, Helsinki, Madrid, } \\
\text { Nice and Lisbon as well asall } \\
\text { short-haul routes from T4. }\end{array}$ \\
\hline $05 / 06 / 08$ & 2.1 & 4 & 5 & 8 long-haul routes from T4. \\
\hline $17 / 09 / 08$ & 2.2 & 4 & 5 & 30 long-haul routes from T4. \\
\hline $22 / 10 / 08$ & 2.3 & 4 & 5 & $\begin{array}{l}11 \text { long-haul routes from T4 } \\
\text { (all remaining routes } \\
\text { excluding Bangkok, } \\
\text { Singapore and Sydney). }\end{array}$ \\
\hline $25 / 02 / 09$ & 3 & 1 & 3 & $\begin{array}{l}\text { Remaining } 5 \text { short-haul routes } \\
\text { from T1. }\end{array}$ \\
\hline
\end{tabular}

Source: Adapted from Heathrow Customer Services (HCS), 2007, p.2

The Gini coefficient was applied to BA flight volumes at Heathrow as a measure of the level of consolidation of flights in T5. Figure 3 clearly shows the Gini coefficient responding as expected to changes in distribution of BA flights between terminals at Heathrow. The Gini coefficient would be expected to reach a value closer to 1 as flights become more concentrated in a single terminal, reflecting a more uneven distribution of flights across 
terminals. Step changes in the Gini coefficient coincide with dates of flight

switches 2.1, 2.2 and 2.3, on which flights were moved into T5. The largest change in Gini coefficient coincides with flight switch 2.2. This would be expected as it was during this switch that 30 flights were moved into $\mathrm{T} 5$, the largest volume of movements since the opening of the terminal (Heathrow Customer Services (HCS), 2007). Switch 3 shows no significant change in Gini coefficient as this switch did not involve moving flights into T5 but rather moving flights from Terminal 1 to Terminal 3, thereby resulting in no overall change in equality of distribution.

Figure 3: Gini coefficient trend

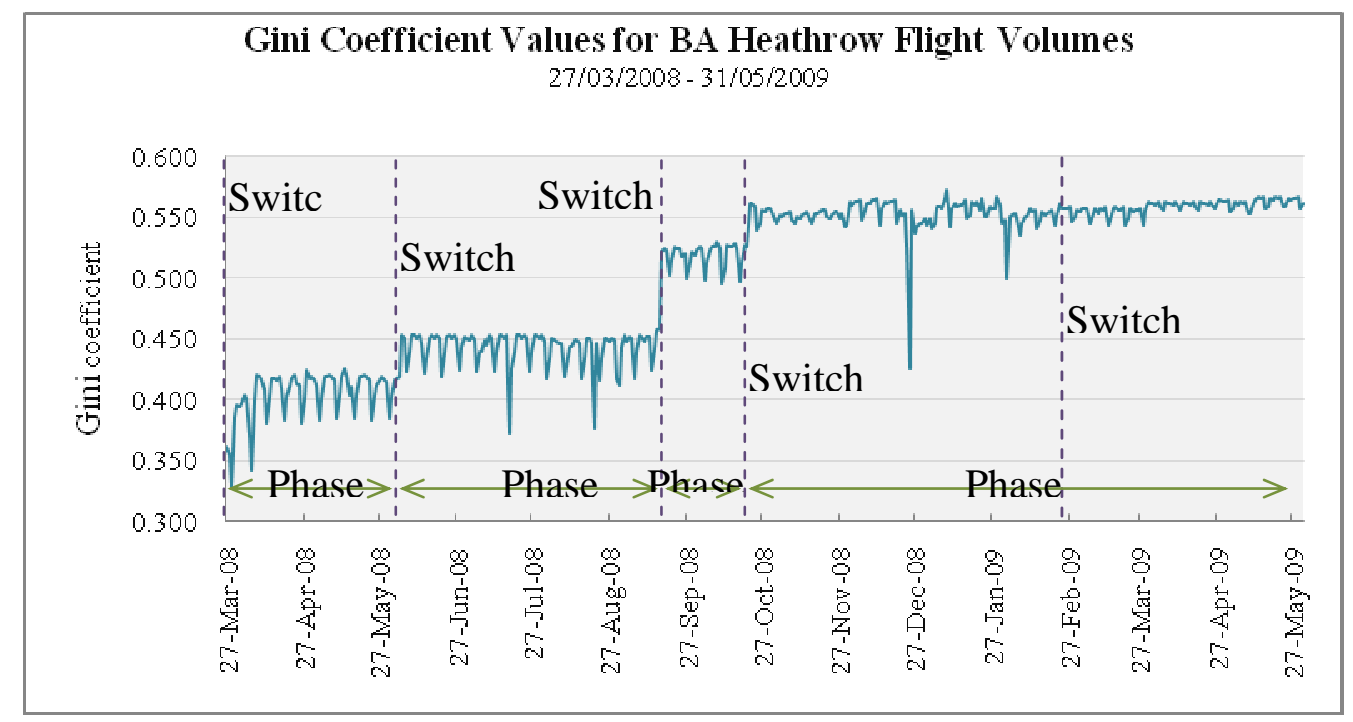

Figure 3 also shows the sensitivity of the Gini coefficient to weekly changes in schedule with consecutive 'dips' in the Gini value on a weekly basis, coinciding with reduced weekend schedules. There are also significant drops in the value on Christmas Day, when BA operates a reduced schedule as well as during times of disruption. It is important to note, however, that a reduction in flights for a particular day will not necessarily result in a 
reduction of the Gini coefficient if flights are reduced in even proportions across all terminals, however, because a uniform reduction of flights across terminals is unlikely in times of disruption or reduced schedule, such times normally coincide with a reduced Gini coefficient. Figure 3 clearly highlights 4 significant phases of time, split by step changes in the Gini coefficient as a result of flight switches 2.1, 2.2 and 2.3. The final switch 3 is considered as negligible in terms of its effect on the Gini coefficient.

\subsection{Outliers}

The transfer baggage performance data presented in this paper is particularly sensitive to flight cancellations, poor weather and other operational disruptions. This volatility can be seen in Figure 2, which shows significant peaking of the trend during times of disruption. It is therefore logical to assume that the dataset will include significant outliers, not least during the first few weeks following the opening of T5 which saw significant disruption, particularly with regards to poor baggage performance. For this reason it is important to examine the distribution of this data, leading to identification and exclusion of extreme values before correlation and ANOVA tests are performed. Possible methods for carrying this out include histogram, stem and leaf and box plot analyses.

The stem and leaf display gives a presentation of distribution, as would a histogram, but also a clear indication of outliers (Bryman and Cramer, 2009). Figure 4, is the stem and leaf display for the transfer baggage performance data under analysis. 
Figure 4: Stem and Leaf Display for Transfer Baggage Performance

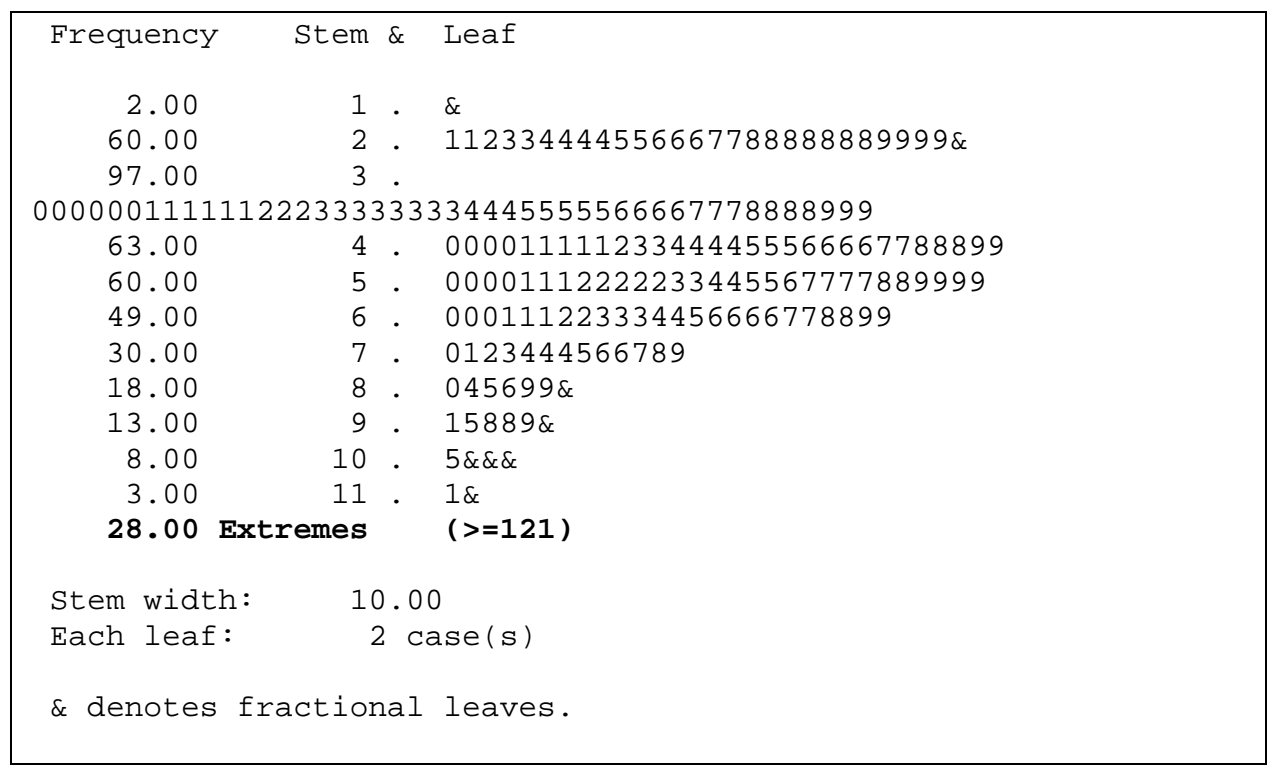

It suggests that on 28 days of the time period studied, 121 or more bags (per 1000 passengers) were short-landed. As a result, these values were excluded for the following ANOVA and correlation tests.

\subsection{ANOVA of Transfer Baggage by Switch Phase}

The gradual nature of movements of flights into T5 was exploited in this paper by comparing transfer baggage means of switch phases (phases between flight switches) using ANOVA.

There is an overall decreasing mean value for transfer baggage performance over switch phases. The standard deviation values of phase 2 and 3 are similar while those of phase 1 and 4 are slightly higher. This is logical considering that phase 1 includes the first few weeks following the opening of T5 during which significant variation in transfer baggage performance occurred. Equally high variation during phase 4 can be explained by weather disruption over the winter, highlighted by the peaking of the 
transfer baggage performance trend over this phase as shown in Figure 2.

Table 3: ANOVA Calculations for Transfer Baggage Performance

\begin{tabular}{|l|l|l|l|l|l|}
\hline & Sum of Squares & df & Mean Square & F & Sig. \\
\hline $\begin{array}{l}\text { Between Groups } \\
\left(\mathrm{v}_{1}\right)\end{array}$ & 68453.91 & 3 & 22817.97 & 80.29 & .000 \\
Within Groups $\left(\mathrm{v}_{2}\right)$ & 113394.52 & 399 & 284.20 & & \\
Total & 181848.44 & 402 & & & \\
\hline
\end{tabular}

The ANOVA in Table 3 has a calculated F of 80.29 indicating that the means between switch phases are significantly different. This result goes someway to suggesting that in fact as BA has gradually consolidated its operations in $\mathrm{T} 5$ over various phases, transfer baggage performance has improved.

\subsection{Correlation Analysis: Gini Coefficient and Transfer Baggage.}

Table 4 shows the calculation of Pearson's $r$ for the correlation and an F test confirms the significance.

Table 4: Pearson's $\boldsymbol{r}$ for the correlation between Gini coefficient and Transfer Baggage Performance

\begin{tabular}{|ll|l|l|}
\hline & & TransferBagPerf & Gini \\
\hline TransferBag & Pearson Correlation & 1 & -.60 \\
Perf & Sig. (2-tailed) & & .00 \\
& $\mathrm{~N}$ & 40 & 40 \\
\hline Gini & Pearson Correlation & -.60 & 1 \\
& Sig. (2-tailed) & .00 & \\
& $\mathrm{~N}$ & 40 & 40 \\
\hline
\end{tabular}

The Pearson's $r$-value of -0.60 shows a negative relationship between the

Gini coefficient and transfer baggage performance i.e. as the Gini 
coefficient increases transfer baggage performance values decrease (fewer bags per 1000 passengers are short-landed).

Although it is important to note that a correlation does not prove causality, what is clear is that the above correlation implies a relationship between BA's consolidation of operations in T5 and the airlines' improving transfer baggage performance. This is consistent with BA's expectations that consolidation of operations in $\mathrm{T} 5$ would significantly improve baggage performance, particularly with regards to transfer baggage, as distances between connecting flights would be shorter with operations in a single terminal (Doherty,2008).

It is important to note, however, that $\mathrm{T} 5$ provided a number of additional benefits in terms of processing passengers and baggage. It is important, therefore, that the above correlation is viewed in this context and that assumptions are not made that consolidation of operations is the sole factor driving improved baggage performance.

\subsection{The Issue of Causality}

Producing a regression equation to formally establish causality would need to include a variety of influences on transfer baggage performance apart from the single user terminal. It is important to note that the move of operations into T5 did not only reflect a change in the level of consolidation of operations but also the implementation of a state-of-the art baggage system with increased automation and capacity which the airline had been lacking in its previous terminals (Doherty, 2008). In order to truly measure 
the benefits of moving flights into a single terminal, those benefits provided by the new terminal in terms of the aforementioned factors would need to be isolated. The dynamic nature of the airport environment means that to keep such factors constant, while only one factor is being investigated, is impossible. Thus, while the above correlations go some way to providing evidence for a causal relationship, they cannot directly prove causality and to model this statistically raises issues with the measurability of factors, for example the level of technological advancement of the baggage processing systems. Both the time and distances which bags travel between transfers are also difficult to measure and no such measure exists at BA. There are possible ways around these difficulties, particularly with regards to the technological advancement of the baggage processing system and its efficiency ${ }^{4}$.

\section{Conclusions}

BA always saw T5 as an opportunity for improving both the airline's transfer performance and overall customer experience and this paper has shown a definite relationship between the consolidation of operations in a single terminal and improved transfer baggage performance. It suggests there are benefits from single-user terminals.

Although the correlation between the Gini coefficient and improved transfer baggage performance cannot be used to prove causality it implies a causal

\footnotetext{
${ }^{4}$ For example, one measure which could reflect this efficiency gain is in the number of containers in the 'full bag stores'. This is where containers are stored when they are packed early for a flight - a large number of these may suggest an efficient system, getting ahead of itself by completing container packing processes well before scheduled departure.
} 
relationship between exclusive terminal use and improved transfer baggage

performance. Furthermore, the ANOVA study highlighted not only a

definite trend of improving transfer baggage performance but also a significant difference between transfer baggage performance averages for various phases, each reflecting varying levels of consolidation of operations in T5. It is important to note, however, that the move of operations into T5 did not only reflect a change in the level of consolidation of operations but also changes in standard operating procedure, equipment, staffing levels and general levels of technology. Thus, while the above correlations go some way to providing evidence for a causal relationship, they cannot directly prove causality and adopting a regression approach to this raises issues of measurability.

As well as the evidence on transfer baggage, significant proportions of passengers felt that finding landside facilities in T5 was easier than in BA's shared terminals when surveyed and results presented in Heinz (2010) also show an improved level of brand awareness, when compared to the airlines previous terminals, where facilities were shared. These findings also have a bearing on the benefits of exclusive use of terminals. 


\section{References}

ACRP, 2008, ACRP Synthesis 8. Common Use Facilities and Equipment at Airports: A synthesis of airport practice.

Bryman, A. and Cramer, D., 2009. Quantitative Data Analysis with SPSS 14, 15 \& 16: A Guide for Social Scientists. New York: Routledge

Dennis, N., 1994. Airline hub operations in Europe. Journal of Transport Geography, 2, 219-233.

Doherty, S., 2008. Heathrow's Terminal 5. Chichester: John Wiley \& Sons.

Heathrow Customer Services (HCS), 2007. Terminal 5 Implementation Forum. Unpublished.

Heathrow Customer Services (HCS), 2010. HCS Microsite LHRPerf. [Online] (updated daily) Available at [access restricted]:

http://horizon.baplc.com/lhrperf/ [Accessed 20 ${ }^{\text {th }}$ January 2010]

Heinz, S.F., 2010, An empirical study of the advantages gained by airlines occupying single-user terminals in terms of transfer baggage performance, brand awareness and passenger way-finding: a case study of British Airways' occupancy of Terminal 5. Unpublished BSc dissertation, Transport Studies Group, Loughborough University.

OAG World Airways Guide, OAG, December 2009.

Reynolds-Feighan, A.,2001. Traffic distribution in low-cost and full-service carrier networks in the US air transportation market. Journal of Air Transport Management, 7, 265-275.

Rodrigue, J., Comtois, C. and Slack, B., 2009. The Geography of Transport Systems. $2^{\text {nd }}$ ed. New York: Routledge.

Saxton, P.J. and Korac-Kakabadse, N., 2003. Understanding strategies for the improvement of inter-organizational performance: cases from the air transport industry, Strategic Change, 12, 151-164.

Wells, A.T. and Young, S., 2004. Airport Planning \& Management. $5^{\text {th }}$ ed. New York; McGraw-Hill. 